\title{
Determination Of Difficulties Encountered By Mothers Having Children With Multiple Disabilities During Early Childhood Special Education Services Process
}

\author{
A.Emel SARDOHAN YILDIRIM", Gönül AKÇAMETE
}

\section{Summary}

Early childhood special education (ECSE) is support services including critical implementations in issues like increasing the quality of life of children with multiple disabilities and their families, providing them with education services and decreasing the negative effects of disabilities and developmental delays (Howard, Williams and Lepper, 2010). Even though early childhood special education, the development and education of these children, and increasing the quality of life of families are included in legal regulations, many difficulties are encountered in their implementation. These problems include arranging family education programs in line with the needs of families, the active participation of family members to the education and the coordination of families with experts regarding the education of children with disabilities. In addition, the support services provided for the families are observed to be insufficient in overcoming difficulties. This study aims to determine the difficulties encountered by the mothers having children with multiple disabilities during early childhood special education services and suggest solutions for the results.

Data were obtained through semi-structured interview technique from qualitative research methods. The study included 6 mothers living in Ankara Province and having children with multiple disabilities whose ages ranged between 1 and 7 years. Data were analyzed by inductive analysis technique. The study found that the mothers felt shocked upon learning the disabilities of their children, the biggest supporters of the mothers when raising their children were their own mothers, they had negative responses from their neighborhood and relatives upon sending their children to school and special education institutions, children with multiple disabilities had difficulties in fulfilling social skills, communicative skills and self care skills in early childhood period and children had difficulties in getting education in classes applying mainstreaming implementations.

According to the findings of the research, in many studies conducted with the families of children with disabilities, since mothers were observed to be the individuals having all responsibilities, they stand alone in raising and the education of children with disabilities without the support of any institutions or persons. In addition, literature includes studies reporting low participation of fathers having children with disabilities in activities regarding their children (Gallagher, and Schopler, 1988; cited by. Riposo,1999). According to another result, mothers stated that the society in which they lives had pity on them and excluded them and their children so they got desperate. However, even though it does not remove the stressing event, the support from the relatives, neighbors and society to mothers having children with disabilities in difficult times makes mothers feel their children and themselves are valuable, decreases their concerns, enables mothers to have more control over themselves and makes them to be eager to try new ways to overcome stress. In addition, the study by Seltzer and Krauss (1989) determined that the social environment of mothers was a better determinant of their quality of life than an official support. The difficulties mothers encounter in ECSE services process includes that children with disabilities could not continue their mainstreaming implementations due to the reasons that their children receive insufficient

\footnotetext{
1 Res. Asst. Ankara University, Faculty of Educational Sciences, emelsardohan@gmail.com

2 Prof. Dr. Ankara University, Faculty of Educational Sciences, gakcamete@ankara.edu.tr
} 
education regarding issues like self care, communication and social skills, teachers have negative attitudes, laws and regulations regarding early childhood special education are not obeyed and the parents of other children do not want children with disabilities in their class. In addition, family education programs are not provided for families. These results are parallel with the results of the study by Kamenopoulou (2012) on blind and deaf small children.

Some suggestions that can be made according to the results of the study are: 1 . Support networks aimed at children with multiple disabilities and their families should be created, 2 . Family oriented programs should be generalized for the families having children with multiple disabilities, 3 . Studies on changing the attitudes of societies of families towards individuals with disabilities should be conducted, 4. Environments for mainstreaming students with multiple disabilities should be prepared. 